\title{
CONSTRUCTION NOISE PREDICTION AND BARRIER OPTIMIZATION USING SPECIAL PURPOSE SIMULATION
}

\author{
Anupama Gannoruwa \\ Janaka Y. Ruwanpura \\ Department of Civil Engineering \\ 2500 University Drive NW, University of Calgary \\ Calgary, A.B. T2N1N4 CANADA
}

\begin{abstract}
Construction projects produce serious environmental pollution and great annoyance to the neighbouring community due to construction noise. This paper presents an application of the special purpose simulation (SPS) language using Simphony software to predict the noise levels generated by construction equipment, tools and machinery at a given reception point for a certain barrier length, as well as the related cost of the barrier wall. To illustrate an application of the developed model, an example has been developed for different noise sources and different activities. The information obtained from the simulation model output will help to utilize the model as a planning tool for optimizing the length and location of noise barriers around a construction site. The tool can be useful for a contractor to develop a noise-control plan using mitigation measures that are acceptable to the owner.
\end{abstract}

\section{INTRODUCTION}

Over the years, an excessive number of construction projects taking place in congested urban areas create pervasive environmental pollution and insufferable noise to the neighbouring community. The major problem of the noise - any disagreeable or undesired sound or other disturbance (Harris, 1991) - that is routinely broadcast into the air is not only that it is unwanted, but also that it negatively affects health and well-being. Problems related to noise include hearing loss, stress, sleep loss, distraction, lost productivity, and a general reduction in the quality of life and opportunities for tranquility. Humans can be both the cause and the victim of noise.

"In Canada, The Environment Protection Act defines vibration and sound that can cause health 'adverse effects' as a contaminant. Adverse effects are defined as harm or material discomfort to any person, or an adverse effect on the health of any person, or loss of enjoyment of normal use of property" (Remmer, 2005, pp. 7). Although noise control and mitigation are a major concern within the transportation industry, there has been little interest in the

environmental impact of construction noise, due to the impermanent nature of construction projects and the fact that they are frequently conducted away from densely populated urban areas (Gilchrist et al., 2003). Construction noise covers inherently loud operations, such as building construction, pile driving, demolition, etc., which often take place in areas that are quiet beforehand and are expected to be quiet again, once the work is completed. Despite its temporary nature, construction of a high-rise structure may result in exposure of nearby residents to objectionable noise levels for a couple of years. In some cases, renewal construction, renovations and repairs can follow one upon another, making the noise a regular nuisance. The noise generated during construction and its influence vary, depending on the nature of the activities, the type and the status of equipment being used, the nature of the surrounding environment, and consideration of environmental and health regulations.

Experienced project teams may have followed the most advanced project planning techniques; however, most construction projects have been plagued with a huge cost for barriers to mitigate noise. The significance of noise control during construction in urban areas and the optimization of barrier length are extremely important in terms of noise nuisance and the cost of the project.

The paper discusses a stochastic simulation model developed using special purpose simulation (SPS) (Hajjar and Abourizk, 2002). The model is capable of predicting noise levels generated by a construction process and may help in determining the location, length and cost of the noise barrier.

\section{BACKGROUND - NOISE}

\subsection{Noise Generators}

Construction projects are commonly associated with excessive noise produced through construction activities and processes. Rock excavation, demolition works, pile- 
driving and blasting operations are some of the major noise generators.

Equipment can also be responsible for noise, which can be generated by the engine, transmission, and processes of pneumatic, milling, grinding, earthmoving, etc. A list of construction equipment and their associated noise levels are given in Table 1.

\subsection{Exposure Levels}

Noise levels are measured in decibels (dBA). Decibels are measured on a scale much like the Richter magnitude scale for earthquakes. A small rise in the decibel level increases the noise significantly. For example, 73 decibels is twice as loud as 70 decibels. Most construction noise is generated from equipment. The decibel levels for some of the construction equipment are listed in Table 1 . The following noise levels can go unprotected for the indicated lengths of time (elCOSH):

- Up to 8 hours - 90 decibels

- Up to 4 hours - 95 decibels

- Up to 1 hour - 105 decibels

Table 1: Noise levels generated by selected construction equipment (noise level measured at $15 \mathrm{~m}$; used equipment $>5$ years old). (Wilson, 1989)

\begin{tabular}{|l|l|}
\hline Equipment & Noise level (dBA) \\
\hline Earth moving & $85-87$ \\
\hline Excavator & $74-92$ \\
\hline Bach hoe & $70-95$ \\
\hline Dozer & $72-92$ \\
\hline Grader & $76-96$ \\
\hline Tractor & $76-98$ \\
\hline Scraper & $85-90$ \\
\hline Paver & $83-95$ \\
\hline Truck \\
\hline Material handling & $74-87$ \\
\hline Concrete mixer & $80-85$ \\
\hline Concrete pump & $70-84$ \\
\hline Movable crane & $68-78$ \\
\hline Stationary & $70-84$ \\
\hline Pump & $64-87$ \\
\hline Generator \\
\hline Compressor & $82-88$ \\
\hline Impact & $80-98$ \\
\hline Pneumatic wrench & $94-106$ \\
\hline Jack hammer/road drills \\
\hline Pile driver \\
\hline Other \\
\hline Vibrator \\
\hline Saw \\
\hline
\end{tabular}

\subsection{Mitigation Strategies}

Noise may reach the listener through the source, from the path where the noise barriers are located, and at the reception point. A schematic diagram of transmission of sound from a source to a reception point, who can be a person, group or a community, is shown in Figure 1.

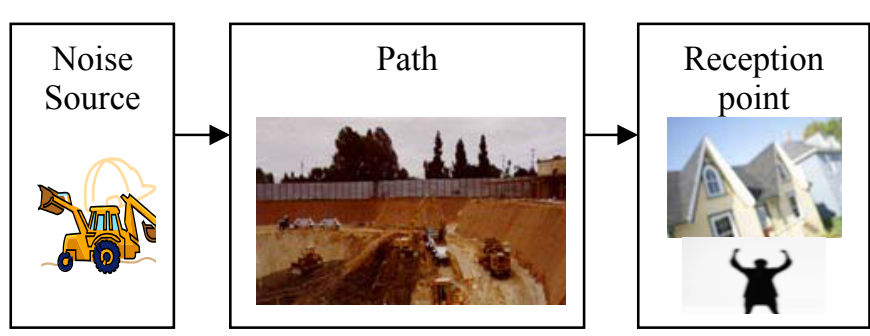

Figure 1: Schematic diagram of transmission of sound from source to reception point

The sources may vary in numbers, and output may vary in time. The path, by which noise reaches a listener from a source, is highly uncertain. Noise can be controlled at the source, on the transmission path and at the reception point. Source control reduces noise emissions in all directions. When the source control does not provide significant reduction in noise, reduction of noise energy transmitted to listeners can be achieved along the transmission path, through building layout, enclosures, absorptions, barriers, etc. Use of noise protective measures controls the noise at the reception point.

The paper discusses controlling noise on the transmission path through barriers because, if costeffective, they are an efficient means for substantial reduction in noise levels. A physical barrier can destroy some of the sound energy by absorbing the sound and/or redirecting the sound. The three strategies for path mitigation are distance, absorption and reflection. When a sound wave encounters a barrier, three interactions take place: (i) transmission through the barrier, (ii) absorption by the barrier, and (iii) reflection back towards the source.

\section{PROCESS OF MODELING NOISE}

A stochastic model for predicting resultant noise level at the reception point and optimizing the length of the noise barrier has been developed. The model takes into account a parent element and four child-level activity elements. The parent element provides stochastic and deterministic values of barrier height, type of barrier, dollar value per square meter of wall, length correction and the allowable noise limit. Each activity element consists of equipment noise emission level and source, reception point height and location, equipment frequencies, number of equipment in use, etc. The model basically applies the following seven equations. 
3.1 Calculation of resultant noise level at the reception point (Gilchrist et al., 2003):

$\mathrm{L}=\mathrm{f}_{\mathrm{s}} \sum\left(\mathrm{S}_{\mathrm{o}}-\mathrm{A}-\mathrm{B}\right)$

\subsection{Calculation of parameters used in (1)}

3.2.1 Calculation of air attenuation value $(A)$ using equation of dissipation (Harris, 1991):

$$
A=A_{\text {div }}+A_{\text {air }}+A_{\text {ground }}+\mathrm{A}_{\text {miscellaneous }}
$$

3.2.2 Calculation of attenuation due to geometrical divergence (Wilson, 1989):

$$
A_{\text {div }}=\mathrm{L}_{1}+20 * \log \left(\mathrm{r}_{1} / \mathrm{r}_{2}\right)
$$

3.2.3 Calculation of attenuation due to ground absorption (Harris, 1991):

$$
A_{\text {ground }}=4.8-\left(2 h_{\mathrm{m}} / r_{2}\right) *\left(17+300 / r_{2}\right)
$$

3.2.4 Calculation of attenuation due to foliage, reflection due to differential heights, and attenuation due to surrounding housing (Harris, 1991):

$A_{\text {miscellaneous }}=\mathrm{A}_{\text {reflection }}+\mathrm{A}_{\text {foliage }}+\mathrm{A}_{\text {housing }}$

3.2.5 Calculation attenuation of reflection due to differential heights (authors' representation based on graphical illustration of Harris, 1991):

$$
A_{\text {reflection }}=-0.0053 * \mathrm{x} 4+0.12 * \mathrm{x} 3-1.1596 * \mathrm{x} 2
$$$$
+4.465 * \mathrm{x}-6.4484
$$

3.2.6 Anticipated reduction of noise due to the proposed sound barrier (Thumann et al., 1976):

$$
\begin{aligned}
& \mathrm{B} \approx \mathrm{IL}=\mathrm{f}_{\mathrm{s}} \sum\{10 \log [3+(20 * \mathrm{f} *(\mathrm{j}-\mathrm{d}) / 342)] \\
& -A \text { ground }\}
\end{aligned}
$$

Definitions for equations are explained further:

In (1),

- $f \mathrm{~s}$ - Synchronization function of construction equipment noise levels

- $i$-Number of pieces of construction equipment operating simultaneously
- $S_{0}$ - noise emission from a given piece of equipment (dBA)

- $A$ - Attenuation of noise due to the distance traveled by the sound energy in open air (dBA)

- $B$ - Anticipated reduction of noise due to the proposed sound barrier, if any (dBA)

- $L$ - Anticipated resultant noise level (dBA) which should be $<=L_{\max }$, the maximum allowable noise limit as defined by the local noise ordinances or the construction documents. For the equipment noise emission level $\left(S_{0}\right)$, range value from table 1 is considered.

In (2),

- $A_{\text {div }}$ attenuation due to geometrical divergence,

- $A_{\text {air }}$ - attenuation due to air absorption,

- $A_{\text {ground }}$ - attenuation due to ground absorption,

- $A_{\text {reflection }}$ - reflection due to differential heights.

In (3),

- geometrical divergence $\left(A_{\text {div }}\right)$ is the spherical spreading of acoustic energy in a free field (unobstructed) from a point source. (Wilson, 1989)

- $\mathrm{L}_{1}$ - noise level at the source

- $\mathrm{r}_{1}$ - calibration distance for $\mathrm{L}_{1}=15.2 \mathrm{~m}$

- $r_{2}$ - distance between source and receiver where $r_{2}>=r_{1}$

Air absorption $\left(A_{\text {air }}\right)$ is likely to be quite small, except for very high frequencies, and can be neglected at short distances (e.g. distances less than several hundred metres). Thus, for the case of construction projects in urban environments $A_{\text {air }}$ can be considered negligible.

In (4)

- $h_{\mathrm{m}}$ - mean height of the propagation path (meters)

- $r_{2}$ - distance between the source and the receiving node (metres).

Ground absorption ( $A_{\text {ground }}$ ) largely depends on the type of ground surface over which the noise is traveling. When calculating the attenuation due to the ground surface, it is important to consider the hardness of the ground surface and the distance traveled by the noise and is obtained from an equation (Harris, 1991).

Three assumptions were made in reference to ground absorption:

(i) the propagation occurs over ground that is nearly all acoustically soft;

(ii) the noise spectrum is particularly broad and smooth, as frequently is the case for a major noise source that consists of many different contributing sources (e.g. construction project); and,

(iii) only the $A$-weighted sound level at the receptor is of interest. (Harris, 1991) 
Attenuation of reflection ( $\left.A_{\text {reflection }}\right)$ is the noise increment or reduction due to the relationship between the source height $\left(h_{\mathrm{s}}\right)$ and the height of the receiving node $\left(h_{\mathrm{r}}\right)$ and can be calculated using the values given in Figures 2, 3 and 4:

- $R \mathrm{~d}$ - direct distance from the source to the receiving node (meters)

- $\quad r \mathrm{r}$ - length of the reflected sound path (i.e., in case a noise barrier exists).

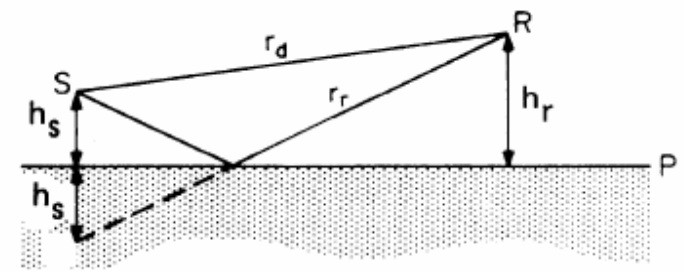

Figure 2: The terms $h_{s}$ and $h_{r}$ for determining $A_{\text {reflection }}$ (Harris, 1991)

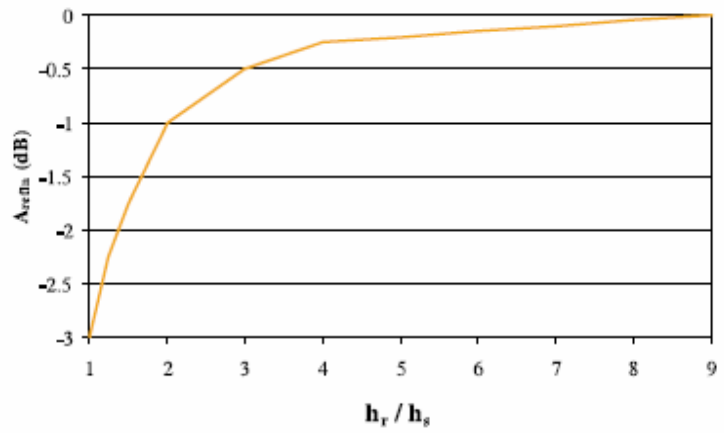

Figure 3: The terms $h_{s}$ and $h_{r}$ for determining $A$ reflection (Harris, 1991)

In developing the model, the graph in Figure 3 was created in Microsoft Excel to find the representative equation.

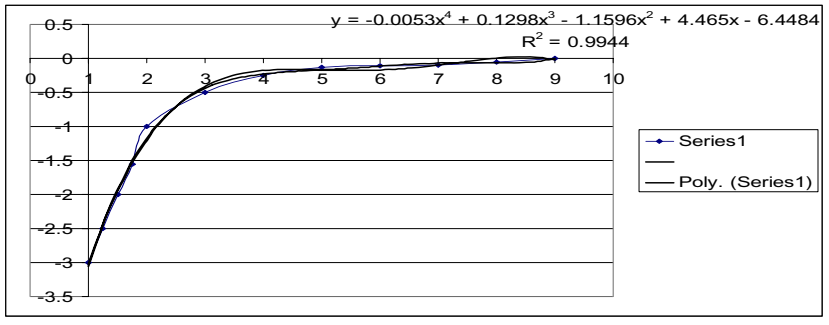

Figure 4: Developed graph using Microsoft Excel for Figures 2 and 3
In (6), $\mathrm{x}$ is the ratio of receiver height (hr) to source height (hs).

A noise barrier stops part of the energy that reaches it as noise, and the other portions pass over and around the barrier. Noise reduction by passing through the barrier is called transmission loss (TL), where as noise reduction over and around is considered as insertion loss (IL). Noise reduction due to the barrier can be used approximately, neglecting the contribution of noise through the barrier because of its order of magnitude, as follows (Thumann et al., 1976):

In (7),

- $B$ - Anticipated reduction of noise due to the proposed sound barrier, if any (dBA)

- $f_{\mathrm{S}}$ - The synchronization function

- $f$ - Equipment noise frequency $(\mathrm{Hz})$,

- $j$ - Length of the transmission path over or around the barrier (paths a, b, or c in Figure 5),

- $d$-distance between the receiving node and the source.

Equation (6) is applied to transmission paths $a, b$, and $c$ to obtain B and the three transmission paths are then synchronized at the receptor using the branch method. (Gilchrist et al., 2002)

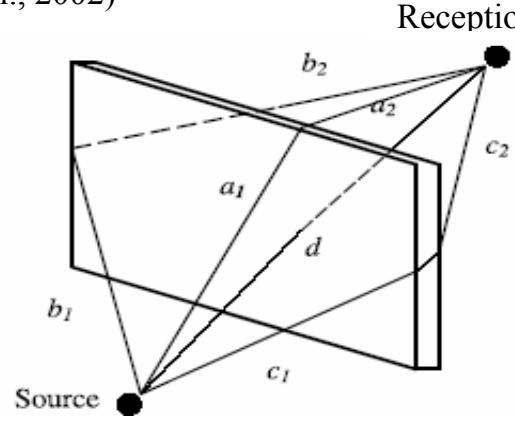

Figure 5: Sound paths used for the insertion loss calculations

The length of the transmission path above the barrier is equal to $a_{1}+a_{2}$. The length of the transmission path around the barrier's left side is $b_{1}+b_{2}$; and, the length of transmission path around barrier's right side is $c_{1}+c_{2}$. The direct distance between the source and the receiver is d. 


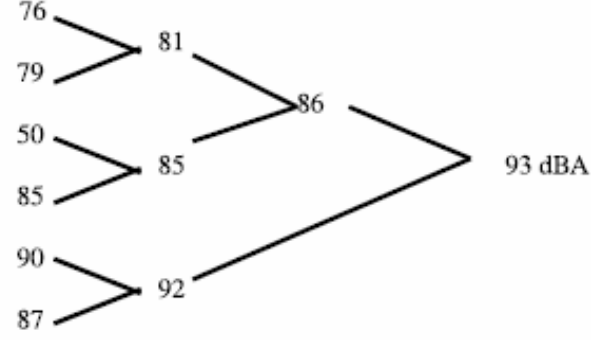

Figure 6: Example of calculating resultant noise (Thumann et al., 1976)

\subsection{Synchronizing Noise Levels using the Branch Method}

The synchronization function $(f \mathrm{~s})$ is found by pairwise comparison of two noise levels at a time by adding a predetermined value (Table 2) to the highest noise level between the two sources (Thumann et al., 1976).

Table 2: Values to be added to the height noise level of a pair (Gilchrist et al., 2002)

\begin{tabular}{|l|l|}
\hline $\begin{array}{c}\text { Difference between } \\
\text { sound source (dBA) }\end{array}$ & $\begin{array}{c}\text { Correction factor to be } \\
\text { added to higher decibel } \\
\text { sound source (dBA) }\end{array}$ \\
\hline $0-1$ & 3 \\
\hline $2-3$ & 2 \\
\hline $3-7$ & 1 \\
\hline $7-9$ & 0.5 \\
\hline 10 and up & 0 \\
\hline
\end{tabular}

Each construction machine is checked for its motionless, in operation and active but static status. The model uses noise levels as shown in Table 3 .

Table 3: Status of equipment

\begin{tabular}{|l|l|}
\hline $\begin{array}{c}\text { Status of } \\
\text { equipment }\end{array}$ & \multicolumn{1}{|c|}{ Noise level used (dBA) } \\
\hline In operation & Generated by the model \\
\hline Active but static & Operating level -10 \\
\hline Motionless & 0 \\
\hline
\end{tabular}

It is assumed that attenuation due to air absorption $\left(A_{\text {air }}\right)$ is neglected at distances less than several hundred metres, except for very high frequencies. Urban areas provide insignificant values of air attenuation. Noise attenuation due to foliage $\left(\mathrm{A}_{\text {foliage }}\right)$ is also insignificant because trees and bushes provide poor barriers for noise transmission. Attenuation due to neighboring housing ( $A_{\text {housing }}$ ) is also not considered, due to its situational dependency.

$$
\mathrm{A}_{\text {housing }}=0.1 * \mathrm{~B} * \mathrm{Sb}
$$

where,

$\mathrm{B}$ is the housing density which is defined as the Total ground floor area of the houses Total area of the ground

$\mathrm{Sb}$ is the length of sound path through the housing area.

Wind and temperature effects are also considered insignificant, because propagation close to the ground for horizontal distances less than about $100 \mathrm{~m}$ does not depend on atmospheric conditions.

\section{STRUCTURE OF THE SIMULATION TEMPLATE}

Simulation is a powerful technique for supporting the decision-making process (AbouRizk et al., 2000). The noise control simulation template is a special purpose simulation tool designed to predict noise levels, optimize barrier length and cost. The template has five modeling elements that depend on the number of activities to be processed during construction. The modeling elements are the starting element, site cleaning, excavation, concreting and roofing, as shown diagrammatically in Figure 7.

The parent element, developed using Simphony 1.05 (Simphony, 2000) coding language, allows the user to input common data that are applicable to all elements at the child level. The user can change the values of the elements in Figure 7, according to the actual situation. This feature generalizes the use of the template in construction work in any area. Input, output and statistics windows are shown in Figures 8, 9 and 10.

The child level comprises activities that are being processed during construction, as shown in Figure 13. 


\section{Global modeling element}

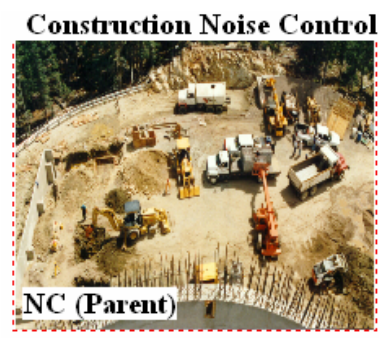

\section{Child level}

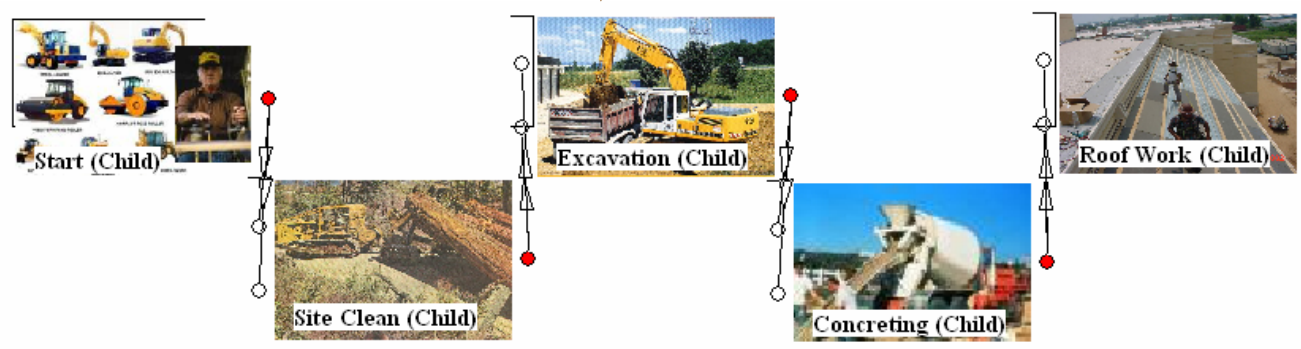

Figure 7: Sample layout of elements

\begin{tabular}{|c|c|c|}
\hline Parameters & Qutputs & Statistics \\
\hline \multicolumn{2}{|c|}{ Parameter } & Value \\
\hline Barrier height & & Uniform $(10.00,22.00)$ \\
\hline Type of Barrier & & Concrete \\
\hline$\$$ per square meter of wal & & Uniform $(90.00,150.00)$ \\
\hline Length_correction & & Uniform $[1.10,1.30)$ \\
\hline allowable_noise_level & & 70.00 \\
\hline
\end{tabular}

Figure 8: Input screen (parent)

\begin{tabular}{|c|c|c|}
\hline Parameters & Dutputs & Statistics \\
\hline & Output & Value \\
\hline Resultant_noise_levelSC & & 38.5440916425139 \\
\hline Resultant_noise_levelEX & & 54.3514364878459 \\
\hline Resultant_noise_levelCO & & 42.7060612958496 \\
\hline Resultant_noise_levelRF & & 41.4285562719441 \\
\hline Overall_noise_level & & 54.3514364878459 \\
\hline Barrier Length_SC & & 39.958665785601 \\
\hline Barrier Length_EX & & 43.1834139531063 \\
\hline Barrier Length_CO & & 26.6854692119415 \\
\hline Barrier Length_RF & & 37.2458416842257 \\
\hline Effective Barrier Length & & 53.5562611931001 \\
\hline Cost_of_wall_SC & & 58473.3798585448 \\
\hline Cost_of_wall_EX & & 112941.855218558 \\
\hline Cost_of_wall_CO & & 48431.9574683956 \\
\hline Cost_of_wall_RF & & 88015.5746912824 \\
\hline Cost_of_wall & & 112941.855218558 \\
\hline
\end{tabular}

Figure 9: Outputs (each activity's noise level, barrier length and the cost of the barrier (parent)) 


\begin{tabular}{l|r|r|r|r|r|r|r|}
\hline \multicolumn{2}{c}{ Parameters } & \multicolumn{3}{c|}{ Qutputs } & \multicolumn{3}{c}{ Statistics } \\
\hline \multicolumn{1}{|c|}{ Statistic } & Runs & Mean & $\begin{array}{c}\text { First } \\
\text { StdDer }\end{array}$ & $\begin{array}{c}\text { Global } \\
\text { StdDer }\end{array}$ & Minimum & Maximum & Graphs \\
\hline Overall_noise_level & 1000 & 58.20 & 0.78 & 2.52 & 45.47 & 70.94 & View \\
\hline Cost_of_wall & 1000 & 100619.87 & 11945.79 & 12436.05 & 52695.12 & 148483.95 & View \\
\hline Effective_Barrier_Length & 1000 & 54.13 & 2.50 & 1.87 & 45.27 & 62.89 & View \\
\hline
\end{tabular}

Figure 10: Statistic - overall noise level, cost of wall and the effective barrier length (parent)

\begin{tabular}{|c|c|}
\hline Parameters & Śtatistics \\
\hline Parameter & Value \\
\hline Buldozer noise emission & Uniform $[70.00,95.00)$ \\
\hline source heightBL $/ \mathrm{hs}[\mathrm{m}]$ & Constant $(5.00)$ \\
\hline source heightDT/ hs(m) & Constant $(5.00)$ \\
\hline receiver height/ hr[m] & Constant $[5.00]$ \\
\hline distance from source To barrier $\mathrm{BL} / \mathrm{r} 3(\mathrm{~m})$ & Constant $(20.00)$ \\
\hline distance from source To barrierDT/ $13(\mathrm{~m})$ & Constant (13.00) \\
\hline distance from receiver To barrier $/ \mathrm{i}(\mathrm{m})$ & Constant (18.00) \\
\hline frequency in $\mathrm{Hz}$ for $\mathrm{BL}$ & Uniform $[125.00,1000.00)$ \\
\hline frequency in $\mathrm{Hz}$ for $\mathrm{DT}$ & Uniform [125.00,1000.00] \\
\hline Status of buldozer & operating \\
\hline Status of dump truck & operating \\
\hline dump truck noise emission & Uniform $[83.00,95.00]$ \\
\hline Tran_distance_above[S side) & Constant $(23.00)$ \\
\hline Tran_distance_above[ $(R$ side $]$ & Constant $(23.00)$ \\
\hline Tran_distance_left(S side) & Uniform $(22.00,29.00)$ \\
\hline Tran_distance_left( $R$ side) & Constant $(20.00)$ \\
\hline Tran_distance_right(S side) & Uniform $(22.00,32.00)$ \\
\hline Tran_distance_right( $R$ side $)$ & Constant $(20.00)$ \\
\hline Tran_distance_above(S side) & Constant $(20.00)$ \\
\hline Tran_distance_above( $R$ side) & Constant $(14.00)$ \\
\hline Tran_distance_left([S side) & Uniform $[24.00,29.00)$ \\
\hline Tran_distance_left( $R$ side) & Constant (18.00) \\
\hline Tran distance right(S side) & Uniform $[23.00 .27 .00]$ \\
\hline Tran_distance_right( $R$ side $]$ & Constant $[18.00]$ \\
\hline Number of buldozers & 2.00 \\
\hline Number of barriers & 1.00 \\
\hline Number of receivers & 1.00 \\
\hline Number of dump trucks & 3.00 \\
\hline
\end{tabular}

Figure 11: Input screen (child) for the activity EXCAVATION

Overall_noise_level - All Runs

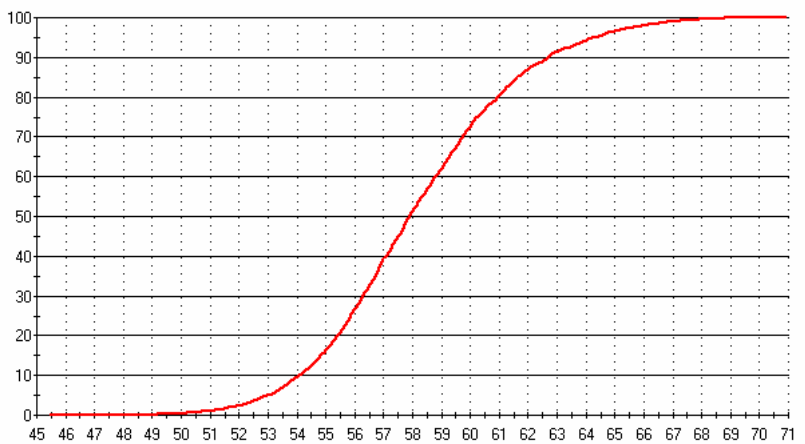

Figure 12: Variation of overall noise level throughout the project
Cost of wall - All Runs

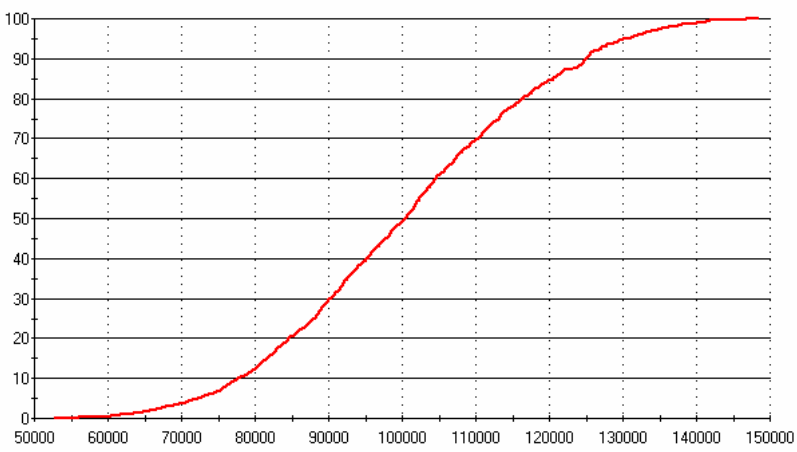

Figure 13: Variation of overall cost of the barrier throughout the project 
Effective_Barrier_Length - All Runs

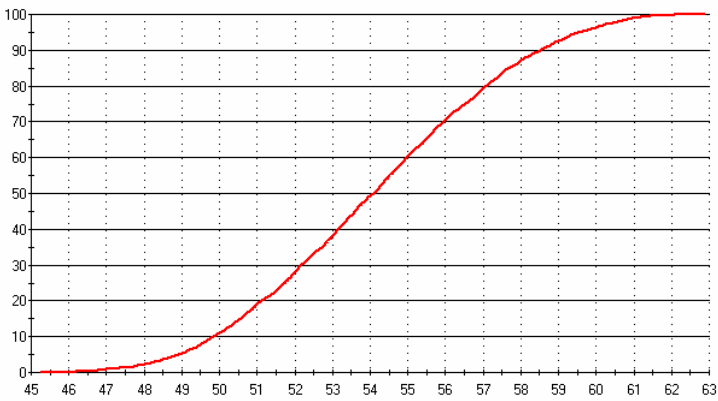

Figure 14: Variation of barrier length throughout the project

Figure 12 expresses the probability of getting a certain noise levels at the reception point. Receiving maximum allowable limit (70 decibels) is $100 \%$. The maximum overall cost and the length of the barrier illustrated in Figure 13 and 14 help making firm decisions at the planning stage.

\section{APPLICATIONS OF SIMULATION TEMPLATE AND CHALLENGES}

Once noise is generated from two noise sources (source 1 and source 2) for an activity, the noise level at the reception point is calculated separately, the results of which are influenced by the barrier employed. Next, the resultant noise is found by synchronization (Thumann et al., 1976) for the specific activity. The branch method allows the resultant noise level from each activity of the construction process to be obtained. The overall noise level is then calculated similarly, by synchronizing all the activity noise levels through the branch method.

If the level is greater than the maximum permitted noise level outlined by municipal bylaws where the construction is taking place, the model provides a warning, by prompting a message "overall noise level exceeds allowable limit". At this stage, barrier length dimensions and location can be changed, thereby making changes to the transmission paths of source $1\left(a_{1}, b_{1}, c_{1}, a_{2}, b_{2}, c_{2}\right)$ and source $2\left(a_{11}, b_{11}, c_{11}, a_{22}, b_{22}\right.$ and $c_{22}$, as shown in Figure 6 ); and, the model is reapplied. When calculating $A_{\text {div }}$, if the source to reception point distance is not greater than calibration distance (15.2 meters), a message will be prompted. The same procedure can be applied to different positions of the reception point for more reliable outputs.

\section{LIMITATIONS OF THE MODEL}

The model does not contain data for different barrier material co-efficients (concrete only) and for the geometry of the barrier. It is also important to differentiate among residential, industrial and commercial zones and to specify different daytime and nighttime maximum noise levels.

\section{CONCLUSION}

The simulation template can be applicable in places where there is a lack of resources and time to conduct research to investigate the noise impact. The model provides a platform that can be applied to various construction projects, particularly if hospitals, courts, etc. are in the vicinity of the construction sites. The model can assist in optimizing the required barriers, which will be beneficial for construction planners and managers to ensure that projects are completed without complains from neighbours. The model requires less resources and less expertise to operate and test. The graphical representations of outputs are also easier to understand and analyze.

The simulation model uses coding and the common template in Simphony 1.05 for elements. Use of the common template with the aid of user elements for modeling is relatively challenging; however, it is a flexible approach. The main challenge of any computer tool is the ability to identify wrong input data that will generate incorrect results. Precise data input, which yields reliable results, is extremely important when using a computer tool.

\section{REFERENCES}

AbouRizk, S. and Y. Mohammed. 2000. Simphony-An integrated environment for construction simulation. In Proceeding of the 2000 Winter Simulation Conference. Piscataway, New Jersey: Institute of Electrical and Electronics Engineers, Inc.

Decibel page, University of New South Wales.

Available via

$<$ http://www.computerhope.com/jargon/d/decibel.htm $>$ [accessed May 13, 2007]

Electronic Library of Construction Occupational Safety and Health (elCOSH). Hazard alert-Construction noise. Available via

$<$ http://www.cdc.gov/elcosh/docs/d0100/d000020/d00 0020.html $>$ [accessed May 14, 2007]

Gilchrist, A., Allouche E.N., and Cowan, D. (2003). Prediction and mitigation of construction noise in an urban environment. Canadian Journal of Civil Engineering, 30(4), 659-672.

Gilchrist, A., Cowan, D., and Allouche, E.N. (2002, June 5-8). Modeling the impact of construction projects on urban environments. Annual Conference of the Canadian Society for Civil Engineering, Montréal, Québec, Canada, 1-12.

Hajjar, D. and AbouRizk, S. (2002). Unified Modeling Methodology for Construction Simulation. Journal of Construction Engineering and Management, 128(2), 174-185.

Harris, C. (1991). Handbook of acoustical measurements and noise control. New York: McGraw-Hill, Inc. 
Remmer, D. and Rocha, J. (2005, August 20-24). Photovoltaic noise barrier-Canada. SESCI 2005 Conference, British Columbia Institute of Technology, Burnaby, British Columbia, Canada.

Simphony (2000). Guide to the development of special purpose simulation templates with Simphony. University of Alberta.

Thumann, A., and Miller, R. (1976). Secrets of noise control. Atlanta, Georgia :The Fairmount Press Inc.

Wilson, C. (1989). Noise control. New York: Harper \& Row.

\section{AUTHOR BIOGRAPHIES}

ANUPAMA GANNORUWA is a M.Sc. student in the Project Management Specialization of Department of Civil Engineering at the Schulich of School of Engineering, University of Calgary, Canada. She earned her B.Sc. (Honours) Civil Engineering from the University of Peradeniya, Sri Lanka. Her M.Sc. thesis is 'Development of an Efficiency Model for Optimum Construction Productivity through Effective Supervision on Worker Performances" conducted in collaboration with number of construction companies in Alberta, Canada.

DR. JANAKA Y. RUWANPURA is the Director and Associate Professor of the Project Management Specialization in the Department of Civil Engineering, Schulich School of Engineering, University of Calgary, Canada. He earned his B.Sc. (Honours) from the University of Moratuwa, Sri Lanka and his M.S. in Construction Management from Arizona State University, and Ph.D. in Construction Engineering and Management from University of Alberta. He has initiated various project management and simulation based research projects with industry support and has published over 80 papers in refereed journals and conference proceedings. His current expertise includes simulation and modeling, risk management, cost forecasting, construction productivity improvement, sustainable development, and project management. Dr. Ruwanpura is an active consultant in Project Management including training and guidance for projects in international countries such as Mexico, Iran, China, Portugal, and Sri Lanka. 